\title{
The Game Between Accounting Oversight Entity and Enterprise Accounting Entity
}

\author{
Qin Rui \\ South China University of Technology, School of Business Administration, Guangzhou, China \\ Email address: \\ 1542774207@qq.com (Qin Rui) \\ To cite this article: \\ Qin Rui. The Game Between Accounting Oversight Entity and Enterprise Accounting Entity. Journal of Finance and Accounting. \\ Vol. 3, No. 4, 2015, pp. 97-102. doi: 10.11648/j.jfa.20150304.15
}

\begin{abstract}
The object of study is the relationship of the game between Accounting Oversight Entity and Enterprise Accounting Entity. Using Nash Equilibrium Theory, the writer establishes the game mathematical model between Accounting Oversight Entity and Enterprise Accounting Entity. Besides, the optimal courses of action of Accounting Oversight Entity and Enterprise Accounting Entity are obtained. What's more, the writer gets the minimum value of fine that Accounting Oversight Entity penalizes Enterprise Accounting Entity beyond accounting standards and analyses the conditions of the game mathematical model. By the way, it accounts for the common sense that the less false accounts, the larger enterprises.
\end{abstract}

Keywords: Accounting Oversight Entity, Enterprise Accounting Entity, Game, Function

\section{Problems Setting}

Currently, almost every enterprise pursues profit maximization in the society. The interests or economic powers of each enterprise are controlled by financial department or accounting department. They will find ways to reduce the outflow of benefits on the basis of the normal. Then, Enterprise Accounting Entity start "battle of wits" with the revenue authorities, who come up with very much "Golden Ideas" about cutting tax or deferred tax, while accountants are trying to find out national policies exactly, in order to achieve a reasonable tax avoidance. Enterprise Accounting Entity reduce the income tax by tax preparation, which reduces the outflow of enterprises' economic interests. Tax preparation is a legitimate way for enterprises to seek to maximize the benefits and should be promoted. However, Enterprise Accounting Entity seek to maximize the benefits by doing false accounts and transferring profits exists. In order to reduce or even eliminate false accounts and safeguard the socialistic market economic order, Accounting Oversight Entity rise in response to the proper time and conditions. Then they have bees in their heads to embellish account books. Meanwhile, Accounting Oversight Entity try to investigate illegal violations. However, there are greater modifications. Of course, Accounting Oversight Entity will continue to improve inspection methods and improve the supervision mechanism to restrain violations.

\section{Analysis and Modeling Assumptions}

To study the issue for a common perspective, the model is not directed against specific companies. So the assumptions for the models are as shown below:

1) Obviously, throughout all enterprises in the society, most of profitable companies are seeking to maximize the interests of business, and then we seize the main contradiction and the main aspects of the main contradiction. Let us assume that the single goal is to seek maximum benefits.

2) False accounts, in the society, are not contributed to their enterprises completely. That is to say that the accounting irregularities or unlawful income are as enterprises' interests. But according to the first hypothesis, we assume that all the false accounts of the Enterprise Accounting Entity are classified as business income within the scope of their own interests.

3) Accountants' behaviors are not necessarily decision making of enterprises' managers, while the interest income is not necessarily been assigned to their enterprises. So we have to simplify the problem, and then we assume that the leadership and accounting staff who do false accounts are as a whole, and they live and die together.[1][2]

4) The majority of people in society are moral, and so do the accountants. In addition, there is a set of accepted moral evaluation system in the society. In order to reduce the 
complexity of the mathematical model, we assume that any persons are not influenced by the moral evaluation system.[3]

5) Some companies have caught the attention of accounting supervision department, then the credibility of enterprises' financial statements is not the same. In order to facilitate the establishment of the mathematical model, we assume that all enterprises are still no lawlessness, in other words, they do not cause the attention of the Accounting Oversight Entity.

6) In some cases, since the servant is not brilliant, limited energy and other reasons, the Accounting Oversight Entity can not find the problem after checking questionable accounting entities. We assume that the inspection results of the Accounting Oversight Entity are accurate at $100 \%$. That is to say, once an enterprise has a financial problem, which is found by the Accounting Oversight Entity.

7) If behaviors of accountants are divided into two aspects: meeting the guidelines of accounting standards or not meeting the guidelines of accounting standards. Then enterprise accounting entities will balance the behavior which get more benefits, and then they make a rational choice.

8) If behaviors of accountants are not the guidelines of accounting standards, the accounting entities have taken the consequence into consideration. The consequence is what results are once they are investigated, and how much influence on their own interests. We believe that the Enterprise Accounting Entity would reduce it to an acceptable level.

9) Accounting Oversight Entity, in the society, is not able to be completely fair. We assume that the Accounting Oversight Entity is completely fair, and stringent levels of the Accounting Oversight Entity are the same. In other words, once a law is put into force, it must be observed and strictly enforced and violators must be brought to justice.

10) According to the regulations, the fine for false accounts is not the benefits of Accounting Oversight Entity, which is treated as revenue. In order to simplify our research questions, we assume that all fine are as the benefits of Accounting Oversight Entity.

11) Whether lucrative or not, which is an important reference standard of checking behaviors.
12) Accounting Oversight Entity and Enterprise Accounting Entity should not be opposite. In our lives, a lot of people don't think so. In order to comply game theory, we assume that Accounting Oversight Entity and Enterprise Accounting Entity are opposite.

\section{Mathematical Model}

\subsection{Symbol Description}

Firstly, the paper gives the mathematical symbols descriptions to help readers understand the models clearly:

1) When the behaviors of Enterprise Accounting Entity are consistent with the guidelines of accounting standards, the profit is denoted by LP (legal profit, using shorthand as variables in the model, it is easy to remember and understand, the same below);

2) When the behaviors of Enterprise Accounting Entity are beyond accounting standards, the profit is denoted by LP (legal profit);

3) The probability is $P_{1}$, when the behaviors of Enterprise Accounting Entity are consistent with the guidelines of accounting standards.

4) The probability is $P_{2}$, when Accounting Oversight Entity checks some Enterprises for their accounts;

5) The total cost of supervision and inspection is TE (total expense);

6) When they find the behaviors of Enterprise Accounting Entity are beyond accounting standards, Accounting Oversight Entity punish Enterprise Accounting Entity for $\mathrm{F}$ (fine);

7) Total profit of Accounting Oversight Entity is TP (total profit);

8) AOE: Accounting Oversight Entity; EAE: Enterprise Accounting Entity.

9) The above variable are non-negative real numbers.

\subsection{Lucrative Table}

In this paper, based on the analysis of preceding research, a model is proposed and the model is shown in Table 1 and Table 2:

Table 1. The lucrative table of Accounting Oversight Entity [4]

\begin{tabular}{lll}
\hline & $\begin{array}{l}\text { Within accounting standards } \\
\left.\text { (probability: } 1-P_{1}\right)\end{array}$ & $\begin{array}{l}\text { Beyond accounting standards } \\
\left.\text { (probability: } P_{1}\right)\end{array}$ \\
\hline Check (probability: $P_{2}$ ) & $-\mathrm{TE}$ & $\mathrm{F}-\mathrm{TE}$ \\
Don't check (probability: $\left.1-P_{2}\right)$ & 0 & $-(\mathrm{IP}-\mathrm{LP})$ \\
\hline
\end{tabular}

Table 2. The lucrative table of Enterprise Accounting Entity.

\begin{tabular}{lll}
\hline & $\begin{array}{l}\text { Within accounting standards } \\
\left.\text { (probability: } 1-P_{1}\right)\end{array}$ & $\begin{array}{l}\text { Beyond accounting standards } \\
\left.\text { (probability: } P_{1}\right)\end{array}$ \\
\hline Check (probability: $P_{2}$ ) & 0 & $-\mathrm{F}$ \\
Don't check (probability: $\left.1-P_{2}\right)$ & 0 & IP - LP \\
\hline
\end{tabular}




\subsection{Optimizing Enforcement of $A O E$}

Lucrative expectation value of AOE:

\subsubsection{Analysis Procedure}

$$
\begin{gathered}
E=\left[-T E *\left(1-P_{1}\right)+(F-T E) * P_{1}\right] * P_{2}+\left[-(I P-L P) * P_{1}+0 *\left(1-P_{1}\right)\right] *\left(1-P_{2}\right) \\
=[F+(I P-L P)] * P_{1}^{*} P_{2}-(I P-L P) * P_{1}-T E^{*} P_{2}
\end{gathered}
$$

Next, the required partial derivative is " $\mathrm{E}$ to $P_{2}$ "

$$
\frac{\partial E}{\partial P_{2}}=F^{*} P_{1}+(I P-L P) * P_{1}-T E
$$

Order $\frac{\partial E}{\partial P_{2}}=0$, and then:

$$
P_{1}=\frac{T E}{F+(I P-L P)}
$$

Put (2) into (1), and then:

$$
E=-\frac{T E^{*}(I P-L P)}{F+(I P-L P)}
$$

The result indicates a profit expectation:

If EAE choose the behavior beyond accounting standards for Enterprise, the probability is:

$$
P_{1}=\frac{T E}{F+(I P-L P)} .
$$

The probability of the behavior within accounting standards for Enterprise is:

$$
E_{1}=\left[-T E *\left(1-P_{1}\right)+(F-T E) * P_{1}\right] * P_{2}+\left[-(I P-L P) * P_{1}+0 *\left(1-P_{1}\right)\right] *\left(1-P_{2}\right)=F * P_{1}-T E
$$

When AOE choose "Don't Check", the probability of the behavior is " $1-P_{2}$ " $\left(P_{2}=0,1-P_{2}=1\right)$, the profit expectation of AOE is:

$$
E_{2}=\left[-T E *\left(1-P_{1}\right)+(F-T E) * P_{1}\right] * P_{2}+\left[-(I P-L P) * P_{1}+0 *\left(1-P_{1}\right)\right] *\left(1-P_{2}\right)=-(I P-L P) * P_{1}
$$

When

$$
P_{1}=\frac{T E}{F+(I P-L P)}, E_{1}=E_{2} .
$$

Therefore, we confirm the probability of accounting once again:

$$
P_{1}=\frac{T E}{F+(I P-L P)}
$$

Probability meets the criteria of operational behavior:

$$
1-P_{1}=1-\frac{T E}{F+(I P-L P)}
$$

That how to select action programs for Accounting Oversight Entity is nothing with profit expectations.
When

$$
\begin{gathered}
P_{1}<\frac{T E}{F+(I P-L P)} \\
\frac{\partial E}{\partial P_{2}}=F^{*} P_{1}+(I P-L P)^{*} P_{1}-T E<0 .
\end{gathered}
$$

So we know that the expected profit function $E$ of Accounting Oversight Entity is a monotonically decreasing function. When $P_{2}=0$, the maximum is $-(I P-L P)^{*} P_{1}$.

When

$$
P_{1}>\frac{T E}{F+(I P-L P)}, \frac{\partial E}{\partial P_{2}}=F^{*} P_{1}+(I P-L P) * P_{1}-T E>0 .
$$

So we know that $\mathrm{t}$ the expected profit function $\mathrm{E}$ of 
Accounting Oversight Entity is a monotonically decreasing function. When $P_{2}=1$, the maximum is $F^{*} P_{1}-T E$.

\subsubsection{Summary}

(1) $P_{1}<\frac{T E}{F+(I P-L P)},\left[1-P_{1}\right]>1-\frac{T E}{F+(I P-L P)}$,

The best action program of AOE is "Don't check". In other words, $P_{2}=0$.

(2) $P_{1}>\frac{T E}{F+(I P-L P)},\left[1-P_{1}\right]<1-\frac{T E}{F+(I P-L P)}$,

The best action program of AOE is "Check". In other words, $P_{2}=1$.

(3) $P_{1}=\frac{T E}{F+(I P-L P)},\left[1-P_{1}\right]=1-\frac{T E}{F+(I P-L P)}$,

Any action programs are the best action program of AOE. In other words, $P_{2} \propto[0,1]$ ( $P_{2}$ is a real number).
Next, we discussed the second case above. In other words, AOE choose "Check". Meanwhile, EAE choose "Beyond accounting standards for Enterprise". If so, how do we punish EAE?[5]

In order for AOE interest loss does not occur, we order $F^{*} P_{1}-T E>0$, so $F>\frac{T E}{P_{1}}$.

Ratio of the total cost and business accounting entity when that penalties must be more than the amount of the Accounting Oversight Entity inspection work choose not to meet the operational conduct of probabilities. The minimum fine is $\frac{T E}{P_{1}} \cdot[6]$

\subsection{Optimizing Action Of EAE}

\subsubsection{Analysis Procedure}

Lucrative expectation value of EAE

$$
E=\left[-F^{*} P_{2}+(I P-L P)^{*}\left(1-P_{2}\right)\right]^{*} P_{1}+\left[0 * P_{2}+0 *\left(1-P_{2}\right)\right]^{*}\left(1-P_{1}\right)=(I P-L P) * P_{1}-(I P-L P) * P_{1}^{*} P_{2}-F^{*} P_{1}^{*} P_{2}
$$

Next, the required partial derivative is "E to $P_{1}$ "

$$
\frac{\partial E}{\partial P_{1}}=(I P-L P)-[(I P-L P)+F] * P_{2}
$$

Order $\frac{\partial E}{\partial P_{1}}=0$, and then:

$$
P_{2}=\frac{I P-L P}{(I P-L P)+F}
$$

Put (4) into (3), and then:

$$
E=0 \text {. }
$$

The result indicates a profit expectation:

If AOE choose the behavior of "Check", the probability is:

$$
P_{2}=\frac{I P-L P}{(I P-L P)+F}
$$

If AOE choose the behavior of "Don't check", the probability is:

$$
1-P_{2}=1-\frac{I P-L P}{(I P-L P)+F} .
$$

From the utility function of EAE, we can see that the profit expectation of EAE is a constant value.

Therefore, when EAE choose the behavior of "Check", the probability is :

$$
P_{2}=\frac{I P-L P}{(I P-L P)+F} .
$$

Meanwhile, the probability of the behavior of "Don't check" is :

$$
1-P_{2}=1-\frac{I P-L P}{(I P-L P)+F} .
$$

EAE choose any behavior, whose profit expectation is no difference.

When EAE choose beyond accounting standards for Enterprise, the probability of the behavior is $P_{1}=1$, the profit expectation of EAE is:

$$
E_{1}=\left[-F^{*} P_{2}+(I P-L P)\left(1-P_{2}\right)\right]^{*} P_{1}+\left[0 * P_{2}+0 *\left(1-P_{2}\right)\right]^{*}\left(1-P_{1}\right)=(I P-L P)\left(1-P_{2}\right)-F^{*} P_{2}
$$

When EAE choose within accounting standards for Enterprise, the probability of the behavior is " $P_{1}$ ” $\left(P_{1}=0,1-P_{1}=1\right)$, the profit expectation of EAE is:

$$
E_{2}=\left[-F^{*} P_{2}+(I P-L P)\left(1-P_{2}\right)\right] * P_{1}+\left[0 * P_{2}+0 *\left(1-P_{2}\right)\right] *\left(1-P_{1}\right)=0 .
$$

When accounting

$$
P_{2}=\frac{(I P-L P)}{(I P-L P)+F}, E_{1}=E_{2}=0
$$

$$
P_{2}=\frac{(I P-L P)}{(I P-L P)+F}
$$

Therefore, we once again confirms the probability of 


$$
1-P_{2}=1-\frac{I P-L P}{(I P-L P)+F}
$$

That how to select action programs for Enterprise Accounting Entity is nothing with profit expectations.

When

$$
\begin{gathered}
P_{2}<\frac{(I P-L P)}{(I P-L P)+F}, \\
\frac{\partial E}{\partial P_{1}}=(I P-L P)-[(I P-L P)+F] * P_{2}>0 .
\end{gathered}
$$

So we know that the profit expectation function $\mathrm{E}$ of Enterprises Accounting Entity is a monotonically increasing function. When $P_{1}=1$, the maximum is $(I P-L P)\left(1-P_{2}\right)-F^{*} P_{2}$.

When

$$
\begin{gathered}
P_{2}>\frac{(I P-L P)}{(I P-L P)+F}, \\
\frac{\partial E}{\partial P_{1}}=(I P-L P)-[(I P-L P)+F] * P_{2}<0 .
\end{gathered}
$$

So we know that the expected profit function $\mathrm{E}$ of enterprises accounting entity is a monotonically decreasing function, made maximum. When $P_{1}=0$, the maximum is 0 .

\subsubsection{Summary}

$$
\text { (1) } P_{2}<\frac{(I P-L P)}{(I P-L P)+F}, 1-P_{2}>\frac{F}{(I P-L P)+F}
$$

The best action program of EAE is "beyond accounting standards for Enterprise". In other words, $P_{1}=1$.

$$
\text { (2) } P_{2}>\frac{(I P-L P)}{(I P-L P)+F}, 1-P_{2}<\frac{F}{(I P-L P)+F}
$$

The best action program of EAE is "within accounting standards for Enterprise". In other words, $P_{1}=0$.

$$
\text { (3) } P_{2}=\frac{(I P-L P)}{(I P-L P)+F}, 1-P_{2}=\frac{F}{(I P-L P)+F}
$$

Any action programs are the best action program of AOE. In other words, $P_{1} \propto[0,1]\left(P_{1}\right.$ is a real number $)$.

\section{The Relationship Between Nash Equilibrium and Various Variables and Model Evaluation}

\subsection{The Relationship Between Nash Equilibrium and Punishment "F"}

Assuming that illegal profits of EAE are determined and the total cost of AOE is determined.

$P_{1}, P_{2}$ to $\mathrm{F}$ :

$$
\begin{aligned}
& \frac{d P_{1}}{d F}=-\frac{T E}{[(I P-L P)+F]^{2}}<0, \\
& \frac{d P_{2}}{d F}=-\frac{(I P-L P)}{[(I P-L P)+F]^{2}}<0 .
\end{aligned}
$$

Therefore, both functions are monotone decreasing function. In other words, as $\mathrm{F}$ decreases, $P_{1}$ and $P_{2}$ are increased. At the same time, as $\mathrm{F}$ increases, $P_{1}$ and $P_{2}$ are decreased.

That is to say, when the behaviors of Enterprise Accounting Entity are beyond accounting standards and they are checked by AOE, the fine is larger and the probability that the behaviors of Enterprise Accounting Entity are beyond accounting standards becomes smaller. On the contrary, when the behaviors of Enterprise Accounting Entity are beyond accounting standards and they are checked by AOE, the fine is smaller and the probability that the behaviors of Enterprise Accounting Entity are beyond accounting standards becomes smaller. At the same time, the probability of AOE's inspection accordingly becomes large. ${ }^{[7][8]}$

Therefore, I propose to deal with life in economic crime and severely punish those who violate the law and discipline, so that EAE will comply with the law. Meanwhile, Accounting Oversight Entity can decrease amount of inspection, which could save money. In short, there is a significant reduction in taxpayers' money, and then social economic environment has been purified.

\subsection{The Relationship Between Nash Equilibrium and the Total Cost of $\mathrm{AOE}$}

Assume that fine must be larger than zero, the illegal profits $(I P-L P)$ are determined.

$$
P_{1}, P_{2} \text { to } T E
$$

$$
\frac{d P_{1}}{d T E}=\frac{1}{(I P-L P)+F}>0, \frac{d P_{2}}{d T E}=0 .
$$

$P_{1}$ is increased with the increase of TE, and with TE decreasing, $P_{1}$ is decreased. $P_{2}$ is independent of $T E$.

That is to say, when the total cost of Accounting Oversight Entity is larger, the probability that the behaviors of Enterprise Accounting Entity are beyond accounting standards is larger, too. At the same time, the total cost of Accounting Oversight Entity is smaller, the probability that the behaviors of Enterprise Accounting Entity are beyond accounting standards is smaller, too. The probability of Accounting Oversight Entity's inspection is independent of the total cost of Accounting Oversight Entity's inspection.

From here we can see that Accounting Oversight Entity should strive to reduce the total cost, so that taxpayers' money can be applied to other key aspects of our society. 


\subsection{The Relationship Between Nash Equilibrium and the Illegal Profits of EAE}

Assuming that fine must be larger than zero, TE is determined .

$$
\begin{aligned}
& P_{1}, P_{2} \text { to }(I P-L P) \\
& \frac{d P_{1}}{d(I P-L P)}=-\frac{T E}{[(I P-L P)+F]^{2}}<0, \\
& \frac{d P_{2}}{d(I P-L P)}=-\frac{F}{[(I P-L P)+F]^{2}}>0 .
\end{aligned}
$$

Therefore, for $(I P-L P)$, function $P_{1}$ is monotone decreasing function, for $(I P-L P)$, function $P_{2}$ is a monotonically increasing function. In other words, $P_{1}$ increases or decreases with $(I P-L P)$ decreasing or increasing, $P_{2}$ increases or decreases with $(I P-L P)$ increasing or decreasing.

In other words, the more illegal profits, the probability that the behaviors of Enterprise Accounting Entity are beyond accounting standards is larger. The fewer illegal profits, the probability that the behaviors of Enterprise Accounting Entity are beyond accounting standards is larger. The more illegal profits of EAE, the larger the probability of AOE's inspection. Meanwhile, the less illegal profits of EAE, the smaller the probability of AOE's inspection. [9][10][11][12][13]

We do a simple reasoning: if the current entities are legitimate accounting entities, that is to say, not only illegal profit is 0 , but also $(I P-L P)$ is at the minimum time. Then the probability of AOE's inspection will minimize, $P_{2}=0$. In other words, AOE choose not to check anyone. If illegal benefit is larger, the optimal action plan for the Accounting Oversight Entity is improving the probability of inspection, and then the probability of illegal benefit will be reduced. As a result, we understand that in order to prevent false accounts of enterprises, Accounting Oversight Entity requires frequent inspections. At the same time, it account for the phenomenon that more false accounts are in small enterprises and less false accounts are in large enterprises.

\section{References}

[1] JIANG Qiyuan and XIE Jinxing. mathematical model. Beijing: Higher Education Press,2012:373-410

[2] JIANG Qiyuan and XIE Jinxing. Mathematical model exercises reference answers. Beijing: Higher Education Press, 2012:98-102

[3] HAN Ying. Mathematical model of the accounting oversight. Xi'an Highway University,2001,21(1)

[4] YU Huan. Relationship of Game Theory and Accounting. Finance and Accounting Monthly, 2015(05)

[5] KAN Liting and YANG Xue. Game Theory in Accounting Research. Economic Vision,2012(2)

[6] BAI Xiuying and ZHANG Xiaoming. Based on Game Theory of Accounting Information Distortion Analysis. Economic Forum,2011(11)

[7] PAN Shi and CHEN Shuping. Economic Analysis and Supervision of listed companies' financial fraud. Jilin University

[8] Walker, Robert. The Accountability Game. Journal of Rehabilitation.1971(4)

[9] Abraham J. Briloff. Unaccountable Accounting: Games Accountants Play. International Journal of Critical Accounting,2010(2)

[10] Kanodia, C. Game Theory Models in Accounting. International series in operations research and management science, 2001(35):49-94

[11] Ding, t.-x.; shi, w.-p. game theory and accounting. journalshangqiu teachers college,2004(1)

[12] Yang, d.-h. Analysis of accounting fraud with the game theory.journal- shanghai jiaotong university Chinese edition2002(36)

[13] Athanasiosmigdalas. Applications of game theory in finance and managerial accounting. operational research,2002(2 